\title{
Chemical disinfestation and metabolic integrity of soil
}

\author{
H. G. VAN FAASSEN and G. LEBBINK \\ Institute for Soil Fertility, Haren (Gr.), The Netherlands
}

Key words 1,3-Dichloropropene Ethoprophos Fumigation Herbicide degradation Metham-sodium Nematicides Organic matter mineralisation

Summary Field disinfestation in autumn with normal or increased dosages of 1,3-dichloropropene, metham-sodium or chloroform, and in spring with ethoprophos, did not, or hardly, affect the degradation in situ of some herbicides applied in spring. However, during laboratory incubation of samples from the disinfested plots, sometimes decreased herbicide degradation rates or increased lag phases were found.

The top few centimetres of the field soil, on which the herbicides were sprayed, apparently largely escaped fumigation. Accordingly, effects of fumigation on herbicide degradation, organic matter and $\mathrm{N}$ metabolism were stronger in samples from the $10-20 \mathrm{~cm}$ layer than in samples from $0-10 \mathrm{~cm}$.

In the laboratory fumigation of soil samples with $\mathrm{CHCl}_{3}$ was much more drastic in inhibiting herbicide degradation, $\mathrm{N}$ mineralisation and nitrification; inoculation with $10 \%$ fresh however, greatly accelerated the recovery of these processes. Therefore, in practice prolonged or drastic effects of chemical soil disinfestation on metabolic integrity of the soil are not to be expected.

\section{Introduction}

Soil disinfestation with fumigants, particularly Telone $(1,3$ dichloropropene about $150 \mathrm{~kg} / \mathrm{ha}$ ) or granular nematicides $(3-10 \mathrm{~kg} / \mathrm{ha})$ is a common practice in potato growing areas in The Netherlands. Fumigants not only kill nematodes but can also affect certain soil microbial activities $^{1,8}$. The question arose whether soil fumigation affects the microbial degradation of herbicides applied afterwards, particularly when the degradation is due to a limited number of species, as may be the case for chloridazon. Between autumn fumigation and spring application of herbicides, however, the soil microflora has time to recover, since fumigants usually disappear rapidly. Granular nematicides are worked into the $0-10 \mathrm{~cm}$ layer in spring at about the same time as some herbicides, so a real possibility of interaction exists.

Mineralisation of organic matter is a common function of the soil microflora. Soil disinfestation kills part of the microflora, but surviving microbes usually take over and rapidly restore the mineralisation rate. Nitrification is more vulnerable to disturbances by pesticides. We investigated the effects of disinfestation on these processes and on herbicide degradation. 
Table 1. Characteristics of the soils used in experiments $1-4 ; 0-20 \mathrm{~cm}$ layer

\begin{tabular}{|c|c|c|c|c|c|c|c|}
\hline Location & Soil type & Texture & $\begin{array}{l}\text { Organic } \\
\text { matter } \\
(\%)\end{array}$ & $\begin{array}{l}\text { Clay } \\
<2 \mu \mathrm{m} \\
(\%)\end{array}$ & $\begin{array}{l}\text { Silt } \\
2-16 \mu \mathrm{m} \\
(\%)\end{array}$ & $\begin{array}{l}\mathrm{CaCO}_{3} \\
(\%)\end{array}$ & $\begin{array}{l}\text { pH } \\
(1 \mathrm{M} \mathrm{KCl}) \\
1: 5\end{array}$ \\
\hline 1. Marknesse & Fluvisol & calc. SL & 2.4 & 18 & 14 & 8 & 7.5 \\
\hline 2. Haren & Podzol & $\mathbf{S}$ & 3.4 & 4 & 3 & - & 4.7 \\
\hline
\end{tabular}

Field and laboratory techniques, established in preliminary experiments in $1979 / 80$, were subsequently used in replicated trials in 1980/83.

\section{Materials and methods}

Because soil fumigation in the field cannot be imitated accurately in the laboratory, field trials were performed principally on two soil types: an acid sandy soil and a calcareous sandy loam soil, a representative of the area $(140,000$ ha) that is periodically disinfested (Table 1$)$. Plots of 9 or $25 \mathrm{~m}^{2}$ were fumigated using a fumigant-injector (Shell) at $18 \mathrm{~cm}$ depth in 16 or 36 spots per $\mathrm{m}^{2}$. The granular nematicide Mocap (ethoprophos) was evenly applied on the soil surface and worked into the top $10 \mathrm{~cm}$ by rotavation. The separate plots were carefully handsprayed with formulated herbicides or mixtures thereof. Application rates ranged from 2.4 to $3.2 \mathrm{~kg}$ active ingredient (a.i.)/ha, or 1.8 to $2.6 \mathrm{mg} / \mathrm{kg}$ soil $(0-10 \mathrm{~cm}$ layer) with a bulk density of $1.25 \mathrm{~g} / \mathrm{cm}^{3}$. Herbicides were applied in spring, except in experiments 3 and $4 \mathrm{~b}$ in autumn. Cropping with sugar beet was preferred to cropping with potatoes, as it permits easy soil sampling. In experiment 2 the soil microflora were stimulated before fumigation by adding dried and ground cow manure enriched with urea $(6000+130 \mathrm{~kg} / \mathrm{ha})$. To suppress volatilisation of fumigants in experiments 2 and 3 , the plots were covered with plastic sheets for 8 to 16 days. The sheets were pervious to oxygen, but as appeared later, also to fumigants.

In addition, larger experimental plots that had been fumigated or treated with granular nematicides for several years with normal field equipment were monitored for herbicide residues (experiment 5 ). Samples of the $0-20 \mathrm{~cm}$ layer were taken from sugar beet and potato plots with different crop rotations.

\section{Analy tical procedures}

For laboratory degradation experiments, soil samples were taken from disinfested and from control plots $(0-10 \mathrm{~cm}$ layer $)$; after sieving $(2.5 \mathrm{~mm})$ and partially air-drying they were homogeneously mixed with the same herbicides as were applied, after sampling, in the fields. Application rate was $5 \mathrm{mg} / \mathrm{kg}$ soil. Duplicate samples, containing $100 \mathrm{~g}$ dry matter, were brought to ca. $50 \%$ water holding capacity and incubated in closed $500-\mathrm{ml}$ bottles at $20^{\circ} \mathrm{C}$ in the dark. Herbicide degradation was monitored by analysis of 5 or $10 \mathrm{~g}$ subsamples at 5 to 10 occasions. When half of each sample was used up, duplicates were combined to allow further sub-sampling. Some soil samples from control plots were fumigated for 24 hours with $\mathrm{CHCl}_{3}$ (Jenkinson and Powlson ${ }^{2}$ ), evacuated to remove its residues and then treated with herbicides, followed by incubation (experiment 4), as a comparison for field fumigation. In some samples the soil microflora were stimulated by mixing $0.5 \%$ ground lucerne with the soil and incubating for one week before fumigation and herbicide addition, in order to test the hypothesis that a metabolically active microflora is more vulnerable to fumigation.

Residues of fumigants and of ethoprophos were extracted with hexane or ethylacetate and analysed using gas chromatography with electron capture or flame-photometric detection $4,6,7$. Herbicide residues were extracted with methanol-water $60 / 40 \mathrm{v} / \mathrm{v}$, followed by reversed phase HPLC with UV-detection at properly selected wavelengths ${ }^{3}$. 
For soil respiration and $\mathrm{N}$ conversion studies, as reliable methods for measuring these in the field were not available, samples were taken to the laboratory immediately after removal of the plastic sheets, for incubation at $20^{\circ} \mathrm{C}$.

$\mathrm{N}$ mineralisation was measured in soil samples with and without lucerne after 6 and 12 weeks.

Nitrification of added $\left(\mathrm{NH}_{4}\right)_{2} \mathrm{SO}_{4}, 100 \mathrm{mg} / \mathrm{kg}$ as $\mathrm{N}$ for soil 1 and $25 \mathrm{mg} / \mathrm{kg}$ as $\mathrm{N}$ for soil 2, was determined after 2 and 6 weeks as $\mathrm{NH}_{4}-\mathrm{N}$ and $\mathrm{NO}_{3}-\mathrm{N}$ in $1 M \mathrm{NaCl}$ extracts.

Urease activity was measured after 0,6 and 12 weeks, as urea hydrolysed in $24 \mathrm{~h}$ (soil 1) or $16 \mathrm{~h}$ (soil 2) at $29^{\circ} \mathrm{C}$ without buffer; urea was extracted with $2 \mathrm{M} \mathrm{KCl}$ and determined colorimetrically?.

Oxygen consumption (B.O.D.) was measured for 2 weeks in $400 \mathrm{~g}$ samples with $0.5 \%$ ground lucerne added, using electrodes developed in our institute to measure partial $\mathrm{O}_{2}$ pressure of the air above the samples and regularly renewing the air.

Populations of free-living nematodes were counted by means of the floatation method of Oostenbrink ${ }^{5}$; numbers of bacteria were determined by spreading $10^{-4}$ to $10^{-7}$ soil dilutions on soil extract agar and incubation for 7 days at $22^{\circ} \mathrm{C}$.

Table 2. Chemical disinfection and metabolic integrity of soil: summary of experiments

\begin{tabular}{lllll}
\hline $\begin{array}{l}\text { Number and year } \\
\text { of experiment }\end{array}$ & $\begin{array}{l}\text { Disinfestants used } \\
\text { in field plots }\end{array}$ & $\begin{array}{l}\text { Dosage time* } \\
\text { and rate } \\
1 / \mathrm{ha} \text { or } \mathrm{kg} / \mathrm{ha}\end{array}$ & $\begin{array}{l}\text { Herbicides used in } \\
\text { field and/or } \\
\text { laboratory }\end{array}$ & $\begin{array}{l}\text { Number of } \\
\text { plots per } \\
\text { soil }\end{array}$ \\
\hline
\end{tabular}

Short-term experiments with soils 1 and 2

Key $\mathrm{T}=$ Telone II $: 92 \%$ 1,3-dichloropropene

$\mathrm{Ma}=$ Monam $\quad: 510 \mathrm{~g} / \mathrm{l}$ metham sodium

$\mathrm{C}=$ Chloridazon

Mc = Mocap 20G : 20\% ethoprophos

$\mathbf{D}=$ Dinoseb

$\mathrm{Cf}=$ Chloroform: $\mathrm{CHCl}_{3}$

$\mathrm{L}=$ Linuron

$M L=$ Monolinuron

$\mathrm{P}=$ Propham

1. $1980 /$ '81

T

$$
\mathrm{Ma}
$$

Mc

Control

2.1982

Cf

Control

3. 1982

Cf

$\mathrm{T}$

Control

4. 1982

a

b
A 150

A 300

S 50

$-$

S 150,300

500,1200

-

A 600,1200

A 600,1200$$
\text { - }
$$

\section{saturated}

$S$ vapour

A 24 hours
Field and Lab:

Cf $(L a b)$

Cf $(L a b)$
$\mathrm{C}+\mathrm{P}$ (both soils)

$M L+L$ (soil 1$)$

D (soil 2)

Field and Lab:

$\mathrm{C}+\mathrm{P}$

Field and Lab:

$\mathbf{C}+\mathbf{P}$
Lab:

$\mathrm{C}+\mathrm{P}$
4

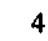

4

4

16

4

6

6

4

pots

16

12

Number of plots (soils)

106 (5)

$66(4)$

C, D, ML, P

Phenmedipham
A variable **

A variable ${ }^{* *}$

Control

\footnotetext{
* Time of application; $\mathrm{A}=$ autumn and $\mathrm{S}=$ spring.

** From a normal dosage every 4 th year to a double dosage annually.
} 
Brief elucidation of the experiments (Table 2)

In experiments 1,2 and 3, herbicide degradation rates were determined both in the field and in the laboratory, although disinfestation was applied only in the field. In experiment 2 we tried to create strong inhibitions and also looked for the effect of stimulating the soil microflora. Because the effect of $\mathrm{CHCl}_{3}$ fell short of our expectations, in experiment 3 we only repeated the highest dosages and compared their effect with the same high dosages of Telone II. The latter completely killed nematodes and was more persistent in the soil than $\mathrm{CHCl}_{3}$. Crop residues of sugar beet in autumn served as a source of microbial stimulation. In this experiment, samples from the $0-10$ and $10-20 \mathrm{~cm}$ layers were separately incubated in the laboratory, because fumigation was suspected to be less efficient in the upper layer. Comparison of results of experiments 2 and 3 might show a different vulnerability of the soil microflora in spring and in autumn samples. In experiment $4, \mathrm{CHCl}_{3}$ fumigation of soil samples in the laboratory should give a maximum effect on the microflora, because escape of the fumigant was prevented. Recovery from fumigation was studied by adding $10 \%$ fresh soil after temoval of $\mathrm{CHCl}_{3}$, imitating a field situation where parts of the soil escape fumigation. Samples fumigated with $\mathrm{CHCl}_{3}$ in the laboratory were tested immediately after removal of the $\mathrm{CHCl}_{3}$ residues. Experiment 5 might demonstrate long-term effects of fumigation.

\section{Results and discussion}

\section{Effects on herbicide degradation}

Fig. 1 shows the degradation rates of herbicides in disinfested soils of experiment 1 . In 13 of 42 cases slower herbicide degradation rates were found in samples from disinfested plots; in 10 after spring application of Mocap, in the other 3 after autumn fumigation with Telone II. Except for chloridazon in one of the Telone II plots (1d) disinfestants did not increase herbicide degradation rates. Conversely, the loam soil plots treated with Mocap showed a delay in degradation of monolinuron and linuron of about 2 weeks (le and $f$ ). The presence of ethoprophos residues, 3.5 and $4.5 \mathrm{mg} / \mathrm{kg}$ soil 1 and 2 , resp., at the start of the laboratory incubation may be the explanation. Granulated ethoprophos and the herbicides were more homogeneously distributed in the samples prepared for incubation than when applied in the field. Herbicide concentrations in the laboratory and in the field are only seemingly different. Herbicide residues in the field are given as $\mathrm{mg} / \mathrm{kg}$ for the $0-10 \mathrm{~cm}$ layer that was sampled, but their distribution was mainly limited to the $0-5 \mathrm{~cm}$ layer. Residues from autumn fumigation were not detected at the time of herbicide application and the microflora had some months to recover.

$\mathrm{CHCl}_{3}$ field fumigation in spring (experiment 2) did not affect the degradation rates of chloridazon and propham, either in the field or in the laboratory. Although the plots were covered with plastic, $\mathrm{CHCl}_{3}$ had disappeared too rapidly from the soil. Herbicide residues were not significantly different in the manure treated plots.

Even $\mathrm{CHCl}_{3}$ fumigation in the laboratory of soil samples taken in spring (experiment 4) had little or no effect on herbicide degradation. 

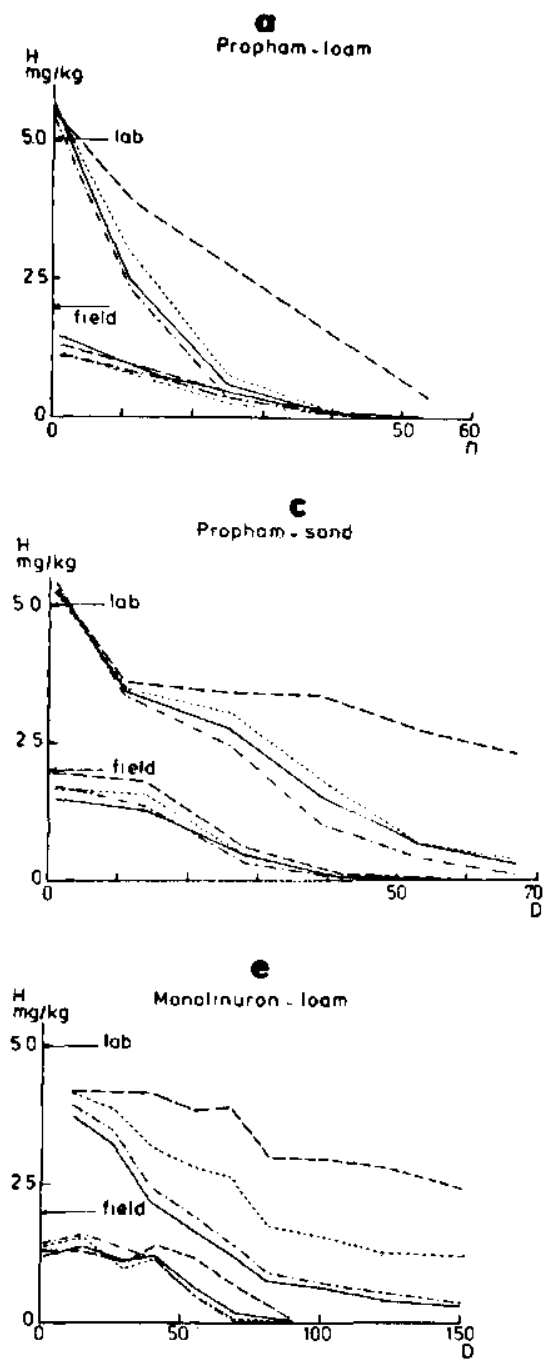

$\mathbf{g}$

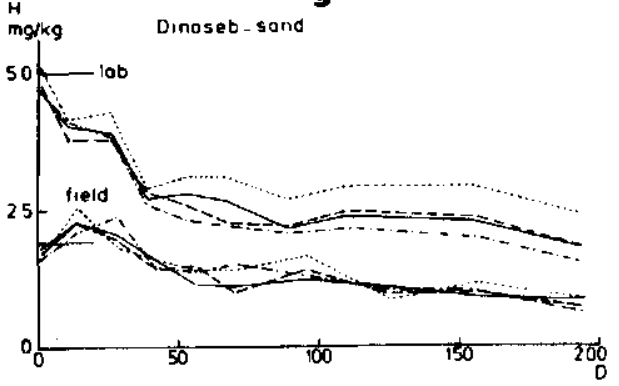

Key.
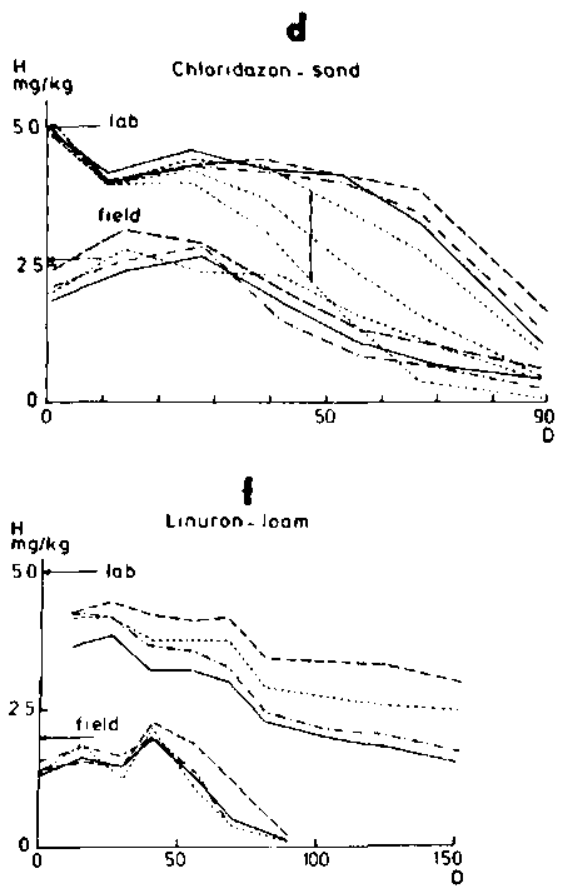

$\mathrm{H}=$ Herbicide residue

D = Days ofter appicicotion

Control

....- TeloneII

- - Monam

-- Mocap

Fig. 1. Degradation of herbicides in disinfested field plots and during incubation of samples from these plots; experiment 1 

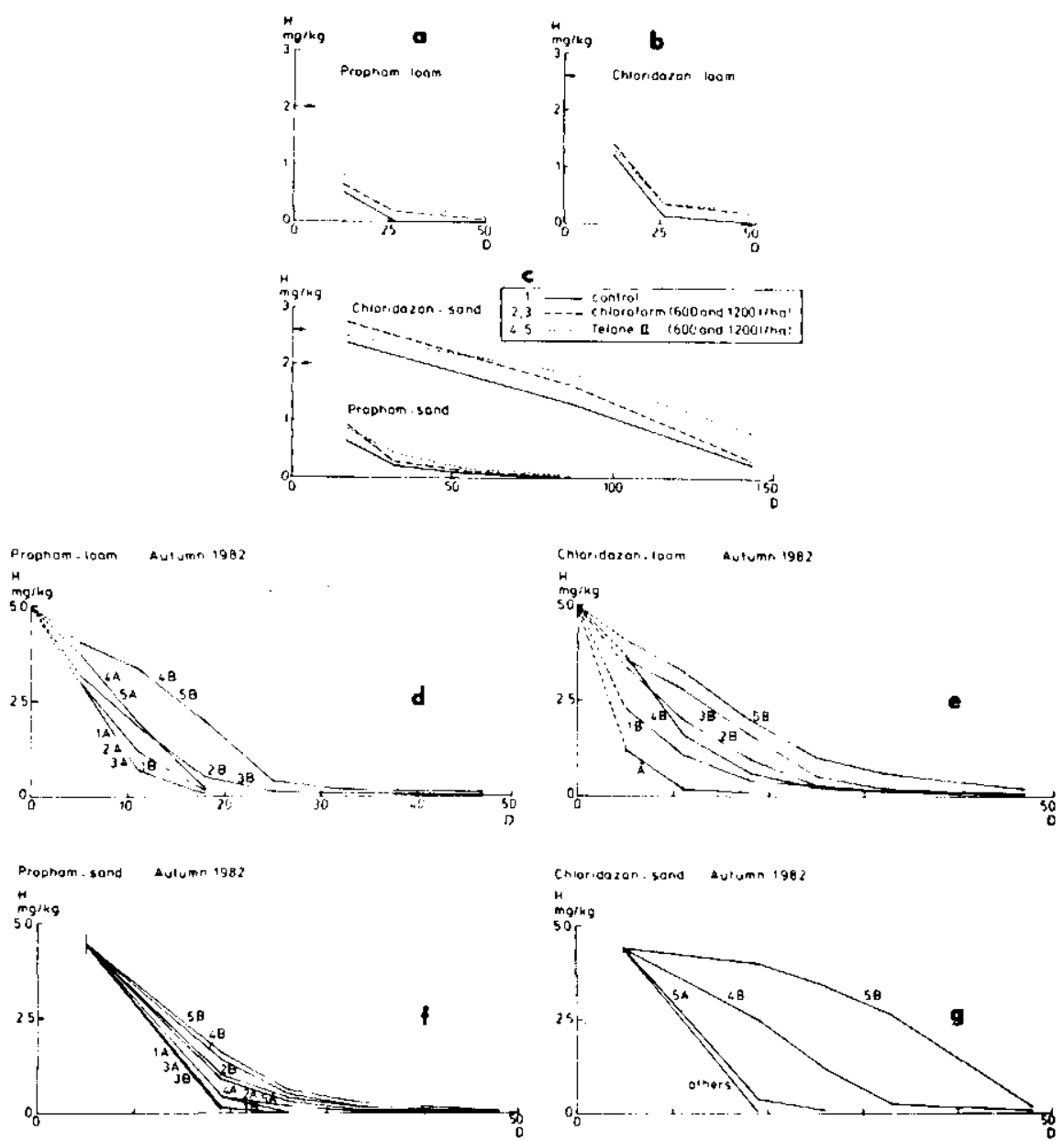

Fig. 2. Degradation of two herbicides in disinfested field plots $(a, b, c)$ and during incubation of samples from these plots $(\mathrm{d}-\mathrm{g})$; experiment $3 . A=$ layer $0-10 \mathrm{~cm}, \mathrm{~B}=$ layer $10-20 \mathrm{~cm}$

However, in samples amended with lucerne and then fumigated, propham degraded much slower, and chloridazon required a long lag phase, whereas lucerne alone increased herbicide degradation rates (Fig. 3a-d).

Field fumigation with high dosages of $\mathrm{CHCl}_{3}$ or Telone II in autumn (experiment 3 ) had little or no effect on herbicide degradation in plots of soil 1 (SL). In plots of soil 2(S) fumigated with Telone II chloridazon disappeared more slowly. Actually, in spring next year chloridazon residues were two to four times higher in the Telone II plots than in the other plots (Fig. 2a-c). In the laboratory, chloridazon and propham disappeared almost at the same rate in all samples from the $0-10 \mathrm{~cm}$ 

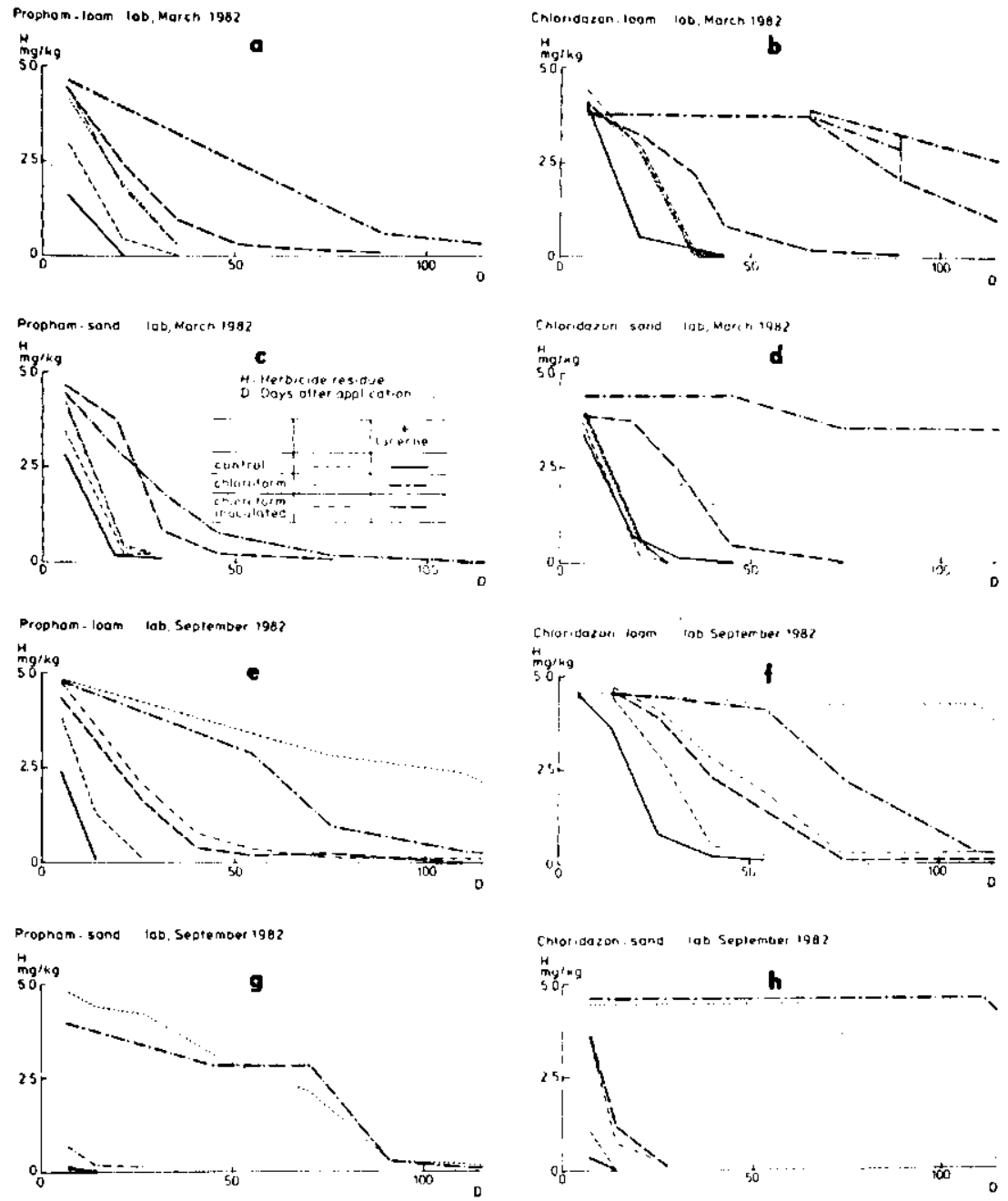

Fig. 3. Degradation of two herbicides in $\mathrm{CHCl}_{3}$ fumigated soil samples with and without lucerne, with and without inoculation with $10 \%$ fresh soils; experiment 4

layer, but in samples from the $10-20 \mathrm{~cm}$ layer of the $\mathrm{CHCl}_{3}$, and especially Telone II plots decreased herbicide degradation rates were found (Fig. 2d-g). The more rapid disappearance of $\mathrm{CHCl}_{3}$ than of 1,3-dcp may be the main explanation. Even at the highest fumigation dosages the herbicide degradation was complete within 30 to 50 days.

$\mathrm{CHCl}_{3}$ fumigation of soil samples taken in autumn (experiment 4b) greatly inhibited or decreased herbicide degradation, with and without lucerne (Fig. 3e-h). The microflora may already have been more active 


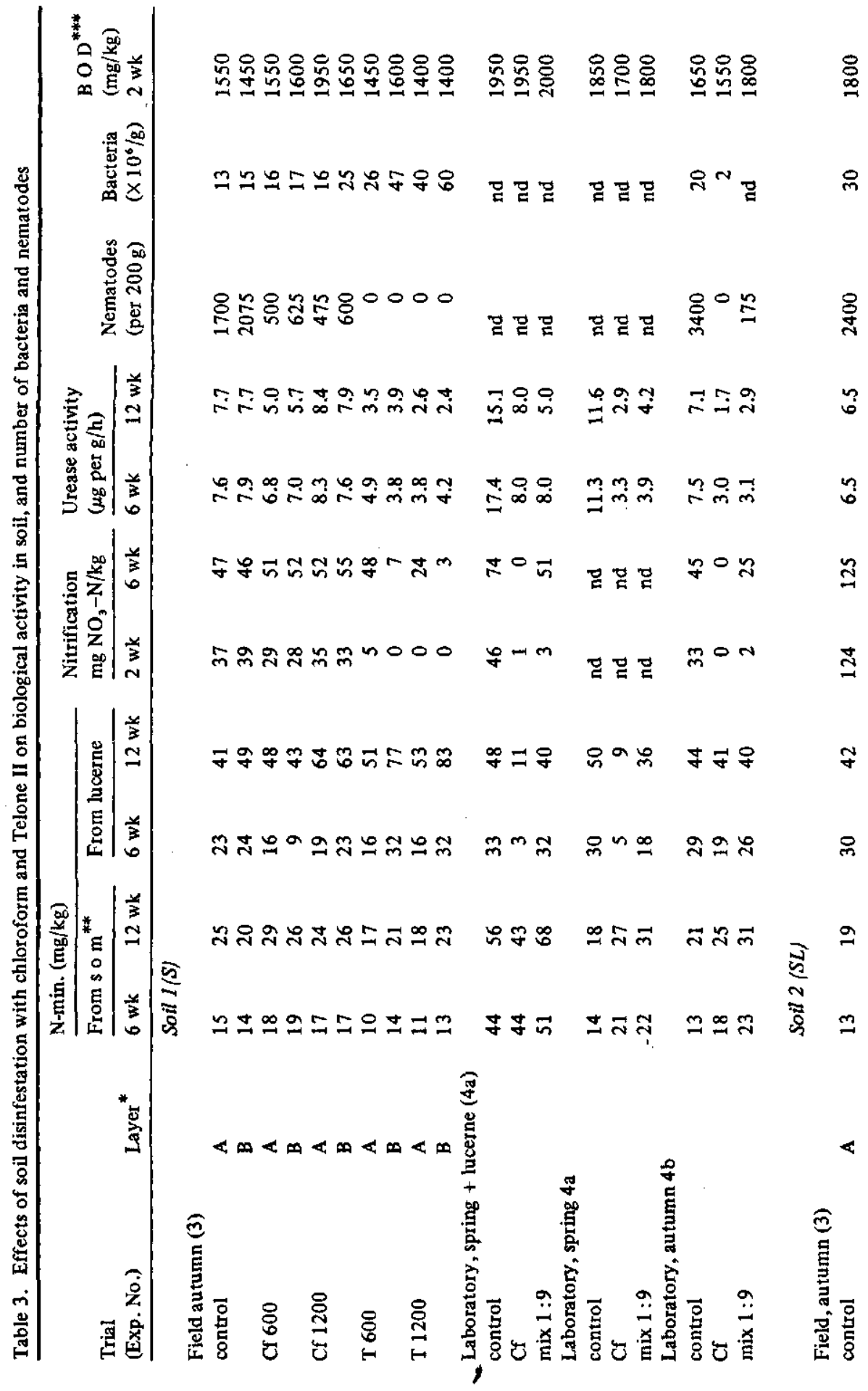




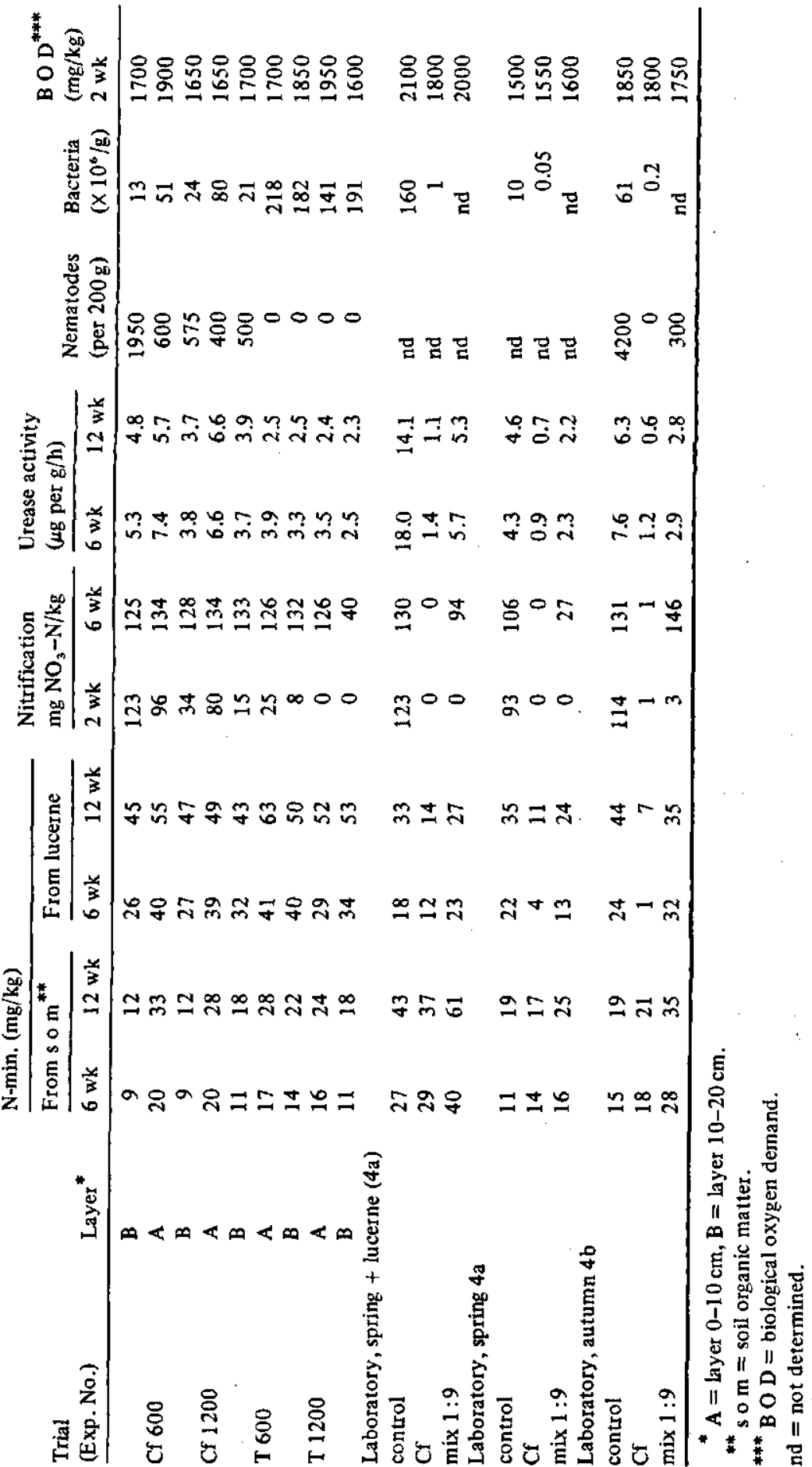


in these samples due to presence of the crop, and therefore more vulnerable than in spring.

The sandy soil samples were taken from the control plots of experiment 2, and thus had a microflora that was adapted to chloridazon and propham. The very rapid degradation of the herbicides in the unfumigated samples confirms this. This may have influenced the effect of the $\mathrm{CHCl}_{3}$ fumigation. Inoculation with $10 \%$ fresh soil rapidly restored herbicide degradation.

Comparison of the results of experiments 3 and $4 \mathrm{~b}$ indicated that, in the field, part of the soil had escaped fumigation. Other experiments confirm the difficulty of fumigating the top few $\mathrm{cm}$ of soil with volatile chemicals. In spring the herbicides will predominantly stay in the top $0-5 \mathrm{~cm}$ of the soil, where fumigation has least effect. This explains why fumigation in the field hardly affected herbicide degradation. In winter, the herbicides can move downwards into a layer where fumigation is more effective.

Monitoring for herbicide residues (experiment 5) showed that annually repeated heavy fumigation in autumn did not affect the degradation of herbicides applied in the following year. The crop rotation and its concomitant use of herbicides had a greater effect on herbicide residue levels than fumigation. Four granular nematicides (Mocap, Temik, Vydate and Curaterr) applied in spring were also found to have no effect on herbicide degradation, but the number of different combinations was too small to allow general conclusions for this class of nematicides.

\section{Effects on biological activity}

Spring application of $\mathrm{CHCl}_{3}$ in the field (Table 2, exp. 2) did not kill the nematodes or affect microbiological activities significantly. Enrichment with dried ground cow manure and urea tended to increase the number of bacteria and enhanced biological activity without causing greater susceptibility to the fumigant. The rapid disappearance of $\mathrm{CHCl}_{3}$ from soil despite the plastic cover may explain 'this. The results of soil disinfestation in the laboratory and field (Table 2, exp. 3) are summarized in Table 3.

Soil fumigation in autumn in the field resulted in unchanged or increased $\mathrm{N}$ mineralisation: the latter due to decomposition of killed biomass. In both soils, but especially in the sandy soil, $\mathrm{N}$ mineralisation after addition of lucerne was stimulated by Telone II, whereas $\mathrm{CHCl}_{3}$ at the highest dose gave this effect only in the sandy soil. Whereas $\mathrm{CHCl}_{3}$ caused a very short retardation of nitrification only in the sandy loam soil, mainly in the $10-20 \mathrm{~cm}$ layer, Telone II strongly inhibited 
nitrification in both soils, particularly in the $10-20 \mathrm{~cm}$ layer and at the highest dosage. In the sandy loam soil, nitrification recovered much faster; after 6 weeks only in the deeper layer at the highest dosage was nitrification still reduced. Near-optimum $\mathrm{pH}$ conditions in the sandy loam soil favoured fast recovery of nitrification.

Whereas Telone II reduced the urease activity in both soils in both layers, $\mathrm{CHCl}_{3}$ was only effective in the deeper layer in the sandy loam soil. The more effective elimination of nematodes, but also the greater increase in bacterial numbers, a well-known phenomenon of partial sterilisation, is indicative of the stronger impact of Telone II. However, no differences in $\mathrm{O}_{2}$ consumption were found. Different behaviour of the soils towards soil fumigation in the field can probably be attributed to differences in physical and chemical qualities and in composition of the microflora.

Soil fumigation with $\mathrm{CHCl}_{3}$ in the laboratory generally resulted in a small increase in $\mathrm{N}$ mineralisation. Addition of $11 \%$ untreated soil further stimulated $\mathrm{N}$ mineralisation. $\mathrm{CHCl}_{3}$ strongly reduced $\mathrm{N}$ mineralisation from lucerne, but at most only slightly reduced $\mathrm{O}_{2}$ consumption. Mixing the sample with $11 \%$ untreated soil largely restored mineralisation of lucerne-N. Urease activity was strongly depressed and adding untreated soil did not completely restore it. The absence of nitrification pointed to the elimination of nitrifiers by chloroform; mixing with $11 \%$ untreated soil did not restore nitrifying capacity within 6 weeks. In cases checked, nematodes were completely killed in both soils and reduction in bacterial number, measured immediately after fumigation, was also drastic.

Field application of $\mathrm{CHCl}_{3}$, even in large amounts, failed to give as strong an impact as could easily be obtained in the laboratory. Only minor effects were found in autumn mainly in the deeper layer of the sandy loam soil.

The effect of soil fumigation with Telone II at 4 to 8 times the normal dosage on nitrification and urease activity was comparable with the effect of mixing $\mathrm{CHCl}_{3}$-treated soil with $11 \%$ untreated soil. The effect on $\mathrm{N}$ mineralisation from lucerne was different: in Telone IItreated soil, mineralisation was stimulated; in the mix it was somewhat reduced.

From the laboratory experiments it can be seen that, to achieve a prolonged reduced microbiological activity in soil, an effective kill of microorganisms is necessary. Such a drastic effect in the field is undesirable because it would lead to reduced soil fertility. Fortunately, the risk of such a drastic effect under field conditions appears to be ' very small. 


\section{References}

1 Anderson J R 1978 Pesticide effects on non-target soil microorganisms. In Pesticide Microbiology. pp. 313-533. Eds. I R Hill and S J L Wright. Academic Press, London.

2 Jenkinson D S and Powlson D S 1976 The effects of biocidal treatments on metabolism in soil. Soil Biol. Biochem. 8, 209-213.

3 Lawrence J F and Turton D 1978 HPLC data for 166 pesticides. J. Chromatography 159, 207-226.

4 Leistra M 1972 Diffusion and adsorption of the nematicide 1,3-dichloropropene in soil. Agric. Research Reports 769. 105 p. Pudoc, Wageningen.

5 Oostenbrink M 1960 Estimating nematode populations by some selected methods. In Nematology. pp. 85-102. Eds. J N Sasser and W R Jenkins. Univ. N. Carolina Press, Chapel Hill.

6 Smelt J H and Leistra M 1974 Conversion of metham sodium to methyl isothiocyanate and basic data on the behaviour of MIT in soil. Pestic. Sci. 5, 401-407.

7 Smelt J H, Leistra M and Voerman S 1977 Movement and rate of decomposition of ethoprophos in soil columns under field conditions. Pestic. Sci. 8, 147-151.

8 Simon-Silvestre G and Fournier J C 1979 Effects of pesticides on the soil microflora. Adv. Agron. 31, 1-92.

9 Zantua M I and Bremner J M 1975 Comparison of methods of assaying urease activity in soils. Soil Biol. Biochem. 7, 291-295. 